\title{
Editorial Issue 17(3-4)
}

On October 30, 2020, an earthquake, whose epicenter was located about $70 \mathrm{~km}$ away from the city center of Izmir, shook the city tremendously. The strong shaking of the earthquake resulted in serious damage or destruction of several hundred structures in the populous city with 4.3 million residents. The damage was due to an unexpected high soil-amplified vibrations very similar to the Mexico City earthquake in 1985. The 42-year-old twin bridges located on the main transportation route in Izmir, were tremendously shaken by the earthquake, but had no observed seismic-induced damage. The twin bridges, suffering from the alkali silica reaction (ASR) over the years, did not even pound to each other despite the small size of longitudinal gap between them. Muratog̀lu et al present the "Unexpected soil amplification effect on seismic performance of highway bridges during the Aegean earthquake of October 2020, Mw 6.6", with focus on the twin bridges in the city of Izmir. In this scope, a bridge inspection has been performed and the twin bridges have been analyzed for the recorded ground motion. Frequency-based analysis techniques such as response spectrum analysis (RSA) are widely used for designing bridges in seismically active regions. Two well-known analysis procedures that underlie RSA are the solution of the eigenproblem and the approximation of the solution to the eigenproblem (i.e., approximation of eigenvectors and eigenvalues) through use of force-dependent Ritz vectors. While frequency-based methods have achieved widespread adoption in practice, certain simplifications remain common, such as neglecting soil-structure interaction (SSI) due to a fixed-base assumption. In "Comparison of eigenanalysis and Ritz vector approaches for response spectrum analysis of soil-pile-bridge systems", Davidson et al employ frequency-based techniques to analyze, assess, and compare results obtained from RSA with use of the eigenanalysis, and separately, Ritz vector approaches. The rupture of a cable in cable-supported bridges is an accidental condition that should be considered during the design phase due the impact that this situation could have on the structural safety of the bridge and users. For that reason, design guidelines suggest carrying out a pseudo-static analysis where the failing cable is replaced by a load of the same magnitude as the pre-rupture tension but applied in the opposite direction and multiplied by a dynamic amplification factor (DAF) between 1.5 and 2.0. Previous studies in cablestayed bridges have shown that the pseudo-static approach may not be suitable. In "Dynamic Amplification Factors of Girder and Cables of Extradosed Bridges during Sudden Cable Failure", Buelvas et al perform computational analysis to estimate the dynamic amplification factors of extradosed bridge girders and cables when sudden failure of an extradosed cable occurs. The main goal of the study is to determine whether the pseudo-static approach suggested in the guidelines is acceptable. Linear response history analyses were performed by using computational models of extradosed bridges in which the girder stiffness and the suspension (lateral or central) and cable layout (fan or harp) of the cables were modified. Using precast concrete elements in bridge structures has emerged as an economic and durable solution to enhance the sustainability of bridges. The northeast extreme tee (NEXT) beams were recently developed for accelerated bridge construction by the Precast/Prestressed Concrete Institute (PCI). To date, several studies on the live load distribution factor (LLDF) for moment in NEXT F beam bridges have been reported. However, the LLDFs for shear in NEXT F beam bridges are still unclear. Through a parametric study, Huang examines "Shear Live Load Analysis of NEXT Beam Bridges for Accelerated Bridge Construction". The parameters covered in the study included bridge section, span length, beam section, number of beams, and number of lanes loaded. A validated finite element (FE) modeling technique was employed to analyze the shear behavior of NEXT $F$ beam bridges under the AASHTO HL-93 loading and to determine the LLDFs for shear in NEXT beam bridges.

Khaled M. Mahmoud, PhD, PE Editor-in-Chief Bridge Technology Consulting New York, New York, USA 